\title{
Warranty and the Risk of Misinforming: Evaluation of the Degree of Acceptance ${ }^{1}$
}

\author{
Dimitar Christozov \\ American University in \\ Bulgaria, Blagoevgrad, \\ Bulgaria \\ dgc@aubg.bg
}

\author{
Stefanka Chukova \\ Victoria University of \\ Wellington, Wellington, \\ New Zealand \\ stefanka@vuw.ac.nz
}

\section{Plamen Mateev, University of Sofia “St. Kliment Ohridski”, Sofia, Bulgaria pmat@fmi.uni-sofia.bg}

\begin{abstract}
Nowadays the product warranty plays increasingly important role in any business transaction. It is a valuable attribute of the product and it is used extensively in marketing and advertising. It is a tool to enforce the competing power of the producer on the market place. There is a vast literature on the product warranty related to the product malfunctioning. In this study we address another type of warranty - the warranty of misinforming, which of great importance in the light of indirect business communication, as in e-commerce. Here, we extend previous studies, aiming to provide a more realistic model for quantifying the risk of misinforming caused by information asymmetry. We propose an approach for evaluating the degree of acceptance of the product with respect to individual tasks, which previously was assumed to be a known constant.
\end{abstract}

Keywords: information asymmetry, misinforming, warranty, risk, degree of acceptance.

${ }^{1}$ This research is partially supported by NFSI-BG, Grant No VU-MI-105/2005

\section{Introduction}

This paper is an extension of our previous findings presented in Christozov, Chukova, and Mateev $(2006,2007)$. We address an open problem posted earlier related to the evaluation of, so called, degree of acceptance of a product by a client. Here, we propose an approach and illustrate a useful procedure for evaluating this degree of acceptance. So, in this paper we provide a detailed outline of an approach for quantifying the risk caused by information asymmetry by briefly

Material published as part of this publication, either on-line or in print, is copyrighted by the Informing Science Institute. Permission to make digital or paper copy of part or all of these works for personal or classroom use is granted without fee provided that the copies are not made or distributed for profit or commercial advantage AND that copies 1) bear this notice in full and 2) give the full citation on the first page. It is permissible to abstract these works so long as credit is given. To copy in all other cases or to republish or to post on a server or to redistribute to lists requires specific permission and payment of a fee. Contact Publisher@InformingScience.org to request redistribution permission. summarizing the ideas shared in Christozov, Chukova, and Mateev (2006, 2007) and elaborating on the evaluation of the degree of acceptance.

The phenomenon of information asymmetry between two parties occurs when one of the parties has better understanding and is better informed on the subject of communication than the other one. There are several aspects of information 
asymmetry that have attracted the interest of researchers. The concept of information misbalance originates in Arrow (1963). His ideas were further developed by Akerlof (1970) in his paper "The Market for 'Lemon's", where the term "information asymmetry" was firstly introduced. Akerlof investigated the influence of asymmetric information on the market value of a commodity and his ideas initiated studies on the impact and usage of the information asymmetry to improve the influence in business relationships. Slovac (1993) studied the asymmetric impact of negative and positive information on the social trust, known as principle of Information Asymmetry or Trust Asymmetry. White and Eiser, 2005 continue this line of research. The role of information asymmetry as a source of misinterpretation, which results in misinforming and/or misleading in a sales/purchase process and might lead to wrong purchase decisions has never been studied at the level it deserves. Some authors (Hseih, Lai, \& Shi, 2006) consider the impact of information asymmetry on the success in business transactions, but they do not go beyond recommendations on how to improve the information process. Christozov, Chukova, and Mateev $(2006,2007)$ proposed a model to quantify the risk of misinforming, caused by information asymmetry and the current paper extends their study.

The outline of this paper is as follows. The next section provides a brief description of the model for quantifying and evaluating the risk of misinforming. It emphasizes on the new approach of collecting data and evaluating the degree of acceptance. Following that we provide an illustrative example. We conclude with a few ideas for further research.

\section{Quantitative Measure of the Risk of Misinforming}

Next, we extend the model for quantifying the risk of misinforming, proposed in Christozov, Chukova, and Mateev (2007) study. One of the main difficulties in quantifying the risk of misinforming is that the risk is subjective, i.e., one and the same message containing information on the product of interest, may convey correct information to some customers and misinform others. This misinformation can have different degrees and consequences for the individual customers within a given group of customers. A message describing the product may inform some of the customers correctly regarding several properties or features of the product, as well as abilities of the product to solve for a particular task or category of tasks, and at the same time, it can misinform them regarding some other features or tasks. Our model aims to allow measuring the risk of misinforming at the task level. In order to simplify the model, we will model only the risk of misinforming between a single producer/seller to a group of customers/buyers regarding a single product. In order to quantify the risk of misinforming, caused by the information asymmetry, we need to identify and measure the factors, which influence this risk

\section{Description of the Product}

We denote the product by $D$. Each product $D$ is represented by a set of $L$ attributes/characteristics. This set of $L$ attributes/characteristics, noted by $C=\left\{C_{l}\right\}, l=1,2, \ldots, L$, describes the structure of the product and, in these study, these attributes/characteristics are assumed to be independent.

\section{Description of the Group of Buyers (Customers) and Group of Tasks}

\section{Description of the group of buyers (customers)}

The group of buyers is denoted by $B=\left\{b_{j}\right\}, j=1,2, \ldots, n$, where $b_{j}$ represents the $j^{\text {th }}$ buyer. Each buyer $j$ has a set of tasks that $\mathrm{s} /$ he needs to solve. 


\section{Description of the Tasks (Problems)}

Let $A_{j}=\left\{a_{i j}\right\}, i=1,2, \ldots, k_{j}$, be the set of $k_{j}$ tasks the $j^{\text {th }}$ buyer needs to solve using the product D. The set of all tasks $A=\left\{U A_{j}\right\}, j=1,2, \ldots, n$, can be structured according to the existence of tasks that are common for many, not necessarily all, buyers. Each common task specifies a particular category within the set of tasks $A$. Let $A_{i}^{*}, i=1,2, \ldots, k$ denote the $i^{\text {th }}$ category of tasks for the set of buyers $B$. We assume that there are tasks common for all buyers, e.g., surfing the Internet. Different buyers have different needs with respect to this task and different degree of acceptance. For example, some buyers will use Internet to download movies and other large files; others will use Internet only for shopping, which does not require transferring of large data sets, etc. The "Internet surfing" is a category and "downloading movies" is a specific task from this category. And of course, different buyers have different measures of what is acceptable performance in using Internet. Then, $A^{*}=\bigcup_{i=1}^{k} A_{i}^{*}$ is the set of all different tasks and, of course, $A^{*}=A$ Set $A$ describes the set of tasks as a union of buyers' tasks, whereas $A^{*}$ is the same set of tasks from task category point of view, (for details, see Christozov, Chukova, and Mateev (2007)). For completeness, we assume that all buyers need to solve for all tasks, but for some of these tasks the buyer's need to solve is equal to zero.

Note that for some of the tasks the buyer needs to solve using the product may not be among the tasks the product is design for. Therefore, the probability that the product is suitable to solve for such tasks is equal to zero.

\section{Degree of acceptance}

Assume that with respect to each task $a_{i j}$, buyer $j$ has a degree of acceptance of the product's attribute $C_{l}$. Denote this degree of acceptance by $q_{i j l}$. This is a number between 0 and 1 , i.e., $0 \leq q_{i j l}$ $\leq 1$. This degree of acceptance $q_{i j l}$ is a measure of the buyer's minimal quality requirement on the attribute $C_{l}$ in order to accept the product $D$ as suitable to solve for task $a_{i j}$. On the other hand, the importance of each of the attributes of the product with respect to solving for particular category of tasks can be measured and expressed in terms of weights, say $w_{i l}$, which are independent from buyer's opinion.

\begin{tabular}{|l|c|c|c|c|c|}
\hline \multicolumn{7}{|c|}{ Table 1. Weights - importance: task-attribute } \\
\hline & \multicolumn{1}{|c|}{ CPU } & RAM & HDD & VRAM & Ethernet \\
\hline Word-processing & 4 & 2 & 2 & 1 & 0 \\
Excel & 4 & 2 & 2 & 1 & 0 \\
e-mail & 2 & 2 & 1 & 0 & 4 \\
Internet & 2 & 2 & 1 & 2 & 4 \\
Complex & 4 & 4 & 4 & 0 & 0 \\
Games & 4 & 4 & 4 & 4 & 2 \\
Movies & 3 & 3 & 3 & 4 & 2 \\
Music & 2 & 2 & 2 & 2 & 2 \\
\hline
\end{tabular}

For example, let the product $D$ is a personal computer (PC) and the attributes of interest are the CPU, RAM, HDD, VRAM and the Ethernet, i.e., $C=\left\{C_{1}=\mathrm{CPU}, C_{2}=\mathrm{RAM}, C_{3}=\mathrm{HDD}\right.$, $C_{4}=$ VRAM, $C_{5}=$ Ethernet $\}$, with $L=5$. Further, for the task category "word-processing", we can 
assign weights of importance to each of the attributes of the product. These weights are assumed to be objective and known in advance. Table 1 provides an example for the weights of importance in the context of the example. The weights are given in a five level scale.

Therefore, an estimation of the degree of acceptance $\hat{q}_{i j}$ of the $j^{\text {th }}$ buyer of the product $D$ with respect to task $a_{i j}$ can be computed as follows:

$$
\hat{q}_{i j}=\sum_{l=1}^{L} q_{i j l} w_{i l} / \sum_{l=1}^{L} w_{i l},
$$

for all tasks the buyer intends, or has a "need", to use the product $D$ to solve for. More on buyer's "need" to solve for a task $a_{i j}$ is given in the next section. Furthermore, if every product is acceptable than $q_{i j}=0$, whereas if $q_{i j}=1$, the buyer has very high quality requirements on $D$ regarding this particular task.

\section{The need of a buyer to solve for a task}

Assume that, the need of the $j^{t h}$ buyer to solve for a task from category $A_{i}{ }^{*}$ is $n_{i j}$, where $0 \leq n_{i j} \leq 1$. If $n_{i j}=0$, this means that the $j^{\text {th }}$ buyer does not need to solve for task $A_{i}{ }^{*}$, while $n_{i j}=1$ means that $b_{j}$ definitely needs to solve for a task from category $A_{i}{ }^{*}$. It is reasonable to assume that if $n_{i j}=0$, then $q_{i j}=0$, i.e., if the buyer $j$ does not need to solve for $a_{i j}$, then every product is acceptable with respect to $a_{i j}$. Therefore, the $j^{\text {th }}$ buyer can be described through the set $b_{j}=\left\{\left(a_{i j}, q_{i j}, n_{i j}\right) \mid a_{i j} \in A_{i}{ }^{*}\right.$, $\left.i=1,2, \ldots, k, 0 \leq n_{i j}, q_{i j} \leq 1\right)$. We assume that for $b_{j}, j=1,2, \ldots, n$, all tasks in $A^{*}$ are presented in his description, but for some of these tasks the corresponding need is equal to zero.

\section{Description of the Seller}

Next, we focus on the description of the Seller as a party in this communication process. The Seller sells the product $D$, which is capable of solving tasks from $A_{i}^{*}$. Let $p_{i}=p\left(A_{i}^{*}\right)$ be the probability that $D$ is capable to solve for $A_{i}^{*}$. If $p\left(A_{i}^{*}\right)=0$, then $D$ is not suitable at all for solving for this category, whereas, if $p\left(A_{i}{ }^{*}\right)=1, D$ is an excellent choice for solving for $A_{i}{ }^{*}$, i.e., $D$ meets any high level of buyer's need, related to the task $A_{i}{ }^{*}$. Further, as a part of its marketing policy, the Seller sends a message to the group of buyers describing the properties/qualities/features of $D$. The content of this message is based on the sellers' evaluation of $p\left(A_{i}{ }^{*}\right)$ and it usually has no information about and cannot take into account the value of $\left\{q_{i j}\right\}, j=1,2, \ldots, n$. In this communication, the information asymmetry is due to the difference between the expertise of the seller and the buyer regarding the product $D$. The usage of a specialized terminology in the message may increase the level of information asymmetry. Based on this message and his/her background, the buyer $j$ assesses the probability $\hat{p}_{i j}=\hat{p}\left(a_{i j}\right)$ that the product $D$ is suitable for solving for task $a_{i j}$. If $n_{i j}=0$ and/or $q_{i j}=0$, then there is no need to estimate $\hat{p}\left(a_{i j}\right)$.

The $j^{\text {th }}$ buyer makes a purchase decision based on the comparison between $\left\{\hat{p}_{i j}\right\}$ and $\left\{q_{i j}\right\}$ over all tasks from the set $A_{j}$. Due to the information asymmetry, the values of $p_{i}$ and $\hat{p}_{i j}$ may differ significantly. Also, these values may differ because $p_{i}$ is evaluated by the Seller for the category of task $A_{i}{ }^{*}$ and not for the particular $a_{i j} \in A_{i}{ }^{*}$, which is of interest to the $j^{\text {th }}$ buyer.

From here onwards, we will follow the notations and assumptions used in Christozov, Chukova, and Mateev (2007). For details on the evaluation of the risk of misinforming and the relationship between this risk and product warranty we refer the reader to Christozov, Chukova and Mateev (2007). Next, we illustrate our ideas and findings, including the evaluation of the degree of acceptance, using an example. 


\section{An Illustrative Example}

\section{Survey}

To illustrate the ideas described in the previous sections, we conducted a survey and collected information needed to evaluate the risk caused by information asymmetry and to analyze its impact on the choice of the product warranty.

In our survey the product $D$ is a personal computer (PC) with a configuration given in the Appendix. This configuration is an updated version of the PC configuration used in Christozov, Chukova, and Mateev (2007). The survey consists of two parts. The first part addresses the assessment of the degree of acceptance of the attributes/components of the product, while the second part is a repetition of the survey used in Christozov, Chukova, and Mateev (2007).

The two parts of the survey were offered to respondents in two, one-hour apart, stages. Firstly, the respondents were asked to fill in Form 1, which addresses the degree of acceptance and how often they need to solve for a particular task. After approximately one hour, the second part of the survey was given out. The time gap between the first and the second part of the survey was introduced because we wanted to reduce the dependence between the information used to evaluate the degree of acceptance for the different PC components and the configuration of the particular PC given in the second part of the survey.

The survey was conducted on two independent groups of respondents. The first part of the survey (Form 1) was identical for both groups. The number of respondents of the two groups was 53 and 10. The second part was divided into two forms. The first form of the second part of the survey offers a choice of two warranty policies: one for malfunctioning and one for misunderstanding, whereas the second form of the second part of the survey extends the list choices by an additional one, which is a mixture between the two policies offered in the first form of the second part of the survey. Each of the groups of respondents was given only one of the forms of the second part of the survey. The responses for Form 1 for both groups were collected in one dataset, while the data from the second part of the survey for the two groups were considered separately.

\section{Results of the Survey}

The two forms of the survey are given in the Appendix. In the next section we present a summary of the data and their analysis, followed by recommendations regarding the best choice of the product warranty. A comparison between our findings and Christozov, Chukova, and Mateev (2007) findings is also provided.

\section{Assumptions and default values for the model parameters}

We assume, that the features of the PC, described in the survey, are evaluated by the producer using $p_{i}$ 's for the tasks, listed below. The values of the $p_{i}$ 's are given in the column on the righthand side:

- Using word processing

- Using spreadsheets, (e.g. Excel) 1.00

- Using e-mail 0.60

- Surfing Internet 0.40

- Solving complicated problems $\quad 1.00$

- Playing Games 0.20

- Watching movies 0.20

- Listening to Music 0.20 
The average value of the degree of acceptance of the PC with respect to each task is given in Table 2 . These were computed using the weights shown in Table 1 and the approach described in the subsection "Degree of acceptance".

\begin{tabular}{|c|c|c|r|r|r|r|r|}
\hline \multicolumn{7}{|c|}{ Table 2. Degree of acceptance by tasks } \\
\hline Word & Excel & e-mail & Internet & Complex & Game & Movies & \multicolumn{1}{c|}{ Music } \\
\hline 0.324 & 0.280 & 0.369 & 0.449 & 0.392 & 0.478 & 0.428 & 0.377 \\
\hline
\end{tabular}

Further, in the assessment of the risk of misinforming, we use the values of the degree of acceptance of the product with respect to the tasks as given in Table 2. In Christozov, Chukova, Mateev (2007) it was assumed that the degrees of acceptance with respect to different tasks are identical, equal to $q=0.5$. In this study, as shown in Table 2, these values are task-dependent, but they still do not take into account the distinctiveness of the buyers.

\section{Summary of the results}

\section{Buyers' risk}

\begin{tabular}{|l|r|r|r|r|r|c|}
\cline { 2 - 7 } \multicolumn{1}{c|}{} & \multicolumn{4}{c|}{ Two forms of warranty } & \multicolumn{3}{c|}{ Three forms of warranty } \\
\hline Category & $\#$ & $\frac{1}{n} \sum_{j=1}^{n} r_{j}^{a}$ & $\frac{1}{n} \sum_{j=1}^{n} r_{j}^{u}$ & $\#$ & $\frac{1}{n} \sum_{j=1}^{n} r_{j}^{a}$ & $\frac{1}{n} \sum_{j=1}^{n} r_{j}^{u}$ \\
\hline Overall & 10 & 0.203 & 0.425 & 53 & 0.213 & 0.438 \\
\hline Optimists & 8 & 0.234 & 0.477 & 23 & 0.265 & 0.515 \\
\hline Pessimists & 1 & 0.075 & 0.188 & 8 & 0.098 & 0.203 \\
\hline Realists & 1 & 0.083 & 0.250 & 22 & 0.200 & 0.443 \\
\hline Warranty 3 months & 2 & 0.191 & 0.420 & 4 & 0.242 & 0.496 \\
\hline Warranty 3 years & 8 & 0.206 & 0.427 & 22 & 0.207 & 0.441 \\
\hline $\begin{array}{l}\text { Warranty 1 month + 1 } \\
\text { year }\end{array}$ & & & & 27 & 0.213 & 0.427 \\
\hline
\end{tabular}

Seller's risk

\begin{tabular}{|l|c|c|}
\cline { 2 - 3 } \multicolumn{1}{c|}{} & Two forms of warranty & Three forms of warranty \\
\hline$R^{s}=$ & 0.450 & 0.431 \\
\hline$R^{u}=$ & 0.450 & 0.432 \\
\hline$R^{a}=$ & 0.220 & 0.222 \\
\hline
\end{tabular}

\section{Interpretation}

The estimated degrees of acceptance, shown in Table 2, are lower than the assumed value of $q_{i j}=$ $q=0.5$ for $i=1,2, \ldots, n$, and $i=1,2, \ldots, k_{j}$ in Christozov, Chukova, Mateev (2007). Of course, these, lower degrees of acceptance affect the level of the risk of misinforming. As expected, and it was confirmed by our analysis, it led to the reduction of the risks. For, example, 0.213 vs. 0.296 for the overall adjusted buyers' risk and 0.438 vs. 0.492 for overall unadjusted buyers' risk in the case of three forms of warranty. This effect was expected, because a lower degree of acceptance 
means, roughly speaking, lower requirements towards the quality of the product, which of course, leads to less number of wrong purchase decisions and respectively lower risk of misinforming.

The risk for the seller shows to be high enough to deserve attention. For this level of risk, because of the domination of optimists, the seller has to offer warranty of the third type. Also, it is clear that a small proportion of respondents recognize their inability to judge properly the qualities of the product. These observations coincide with the findings in Christozov, Chukova, Mateev (2007).

\section{Conclusion and Future Work}

The studies on the risks of misinforming are still in a very early stage, but the results obtained so far show that this risk exists and it could provide the Sellers with information, useful in indirect trading, which became very popular during the last decade through the Internet. In addition, designing a feasible warranty policy, as an instrument to enhance the trust between parties, requires cost-benefit analyzes based on quantified assessment of the risk of misinforming. In this study, the proposed approach to quantify the risk caused by information asymmetry is mostly practical and it needs further improvement and development. Our future work will address several interesting issues such as: the structure of the product, allowing for dependent attributes, as well as the study of some stochastic relationships between the parameters of the model. Of course, our ultimate goal is to apply our model to a real business enterprise.

\section{References}

Akerlof, G. A. (1970). The market for 'Lemon's: Quality uncertainty and the market mechanism. Quarterly Journal of Economics, 84(3), 488-500.

Arrow, K. (1963). Uncertainty and the welfare economics of medical care. American Economic Review.

Christozov D. (1999). Evaluation of the quality of an option compare to its alternatives. In Polis, Dontchev, Kall, Lasiecka, Olbrot Systems Modelling and Optimization Proceedings of the 18th IFIP TC7 Conference (Research Notes in Mathematics Series), 396, pp. 318-326. CRC Press.

Christozov, D., Chukova, S., \& Mateev, P. (2006). A measure of risk caused by information asymmetry in e-commerce. Journal of Issues in Informing Science and Information Technology, 3, 147-158. Retrieved from http://informingscience.org/proceedings/InSITE2006/IISITChri169.pdf

Christozov D., Chukova S., \& Mateev P. (2007). On the relationship between warranty and the risk of information asymmetry. Journal of Issues in Informing Science and Information Technology, 4, 235-249. Retrieved from http://proceedings.informingscience.org/InSITE2007/IISITv4p235-249Chri295.pdf

Hseih. C-T., Lai, F., \& Shi, W. (2006) Information orientation and its impact on information asymmetry and e-business adoption: Evidence from China's international trading industry, Industrial Management \& Data Systems, Vol. 106, Issue 6, pp. 825-840.

Slovac, P. (1993). Perceived risk, trust, and democracy. Risk Analysis, 13, 675-682.

White, M., \& Eiser, R. (2005). Information specificity and hazard risk potential as moderators of trust asymmetry. Risk Analysis, 25(5), 1187-1198.

\section{Appendix}

Part 1 of the survey consists of eight identical tables, one for each of the tasks given in Table 1. Here, in the Appendix, we show only two of these tables, for word-processing and for using spreadsheets. 


\section{Dear students,}

We are studying the impact of information exchange on business transactions and purchase decisions and the way this exchange affects the customer choice.

\section{We are running the following experiment:}

Firstly, we need information about your needs and applications, you are going to use, as well as the minimal configuration of the PC you need to run the application in a way suitable to your needs.

Second, assume that you are offered the opportunity to buy a personal computer (PC) at a highly attractive price (say, the sale price is $30 \%$ less than you would expect to pay). You have to assess the level the given PC configuration meets your needs to run applications you need as well as the warranty policy, which suits the best to your purchase decision.

\section{Part 1.}

Form 1: Please, select the minimal configuration of the PC to meet your needs for using it for:

a) Using word processing

\begin{tabular}{|l|c|c|c|c|c|}
\hline \multirow{2}{*}{ PC property } & Low & & & & High \\
\cline { 2 - 6 } & 0 & 1 & 2 & 3 & 4 \\
\hline \multirow{2}{*}{$\mathrm{CPU}$} & $0.35 \mathrm{GHz}$ & $1 \mathrm{GHz}$ & $1.6 \mathrm{GHz}$ & $2.4 \mathrm{GHz}$ & $4.8 \mathrm{GHz}$ \\
\cline { 2 - 6 } & & & & & \\
\hline \multirow{2}{*}{ RAM } & $256 \mathrm{MB}$ & $512 \mathrm{MB}$ & $1 \mathrm{~GB}$ & $2 \mathrm{~GB}$ & $4 \mathrm{~GB}$ \\
\cline { 2 - 6 } & & & & & \\
\cline { 2 - 6 } & & & & & \\
\multirow{2}{*}{$\mathrm{HDD}$} & $16 \mathrm{~GB}$ & $64 \mathrm{~GB}$ & $256 \mathrm{MB}$ & $512 \mathrm{MB}$ & $1 \mathrm{~GB}$ \\
\hline \multirow{2}{*}{ VRam } & & & & & $10 \mathrm{~Gb}$ \\
\hline \multirow{2}{*}{ Ethernet } & $56 \mathrm{Kbs}$ & $10 \mathrm{Mbs}$ & $100 \mathrm{Mbs}$ & $1 \mathrm{Gbs}$ & $10 \mathrm{~Gb}$ \\
\cline { 2 - 6 } & & & & & \\
\hline
\end{tabular}

\begin{tabular}{|l|c|c|c|c|c|}
\hline \multirow{2}{*}{$\begin{array}{l}\text { How often you use PC for word proc- } \\
\text { essing }\end{array}$} & Low & & & & High \\
\cline { 2 - 7 } & never & yearly & monthly & weekly & daily \\
\hline & 0 & 1 & 2 & 3 & 4 \\
\hline
\end{tabular}

b) Using spreadsheets, (e.g. Excel)

\begin{tabular}{|l|c|c|c|c|c|}
\hline \multirow{2}{*}{ PC property } & Low & & & & High \\
\cline { 2 - 6 } & 0 & 1 & 2 & 3 & 4 \\
\hline \multirow{2}{*}{$\mathrm{CPU}$} & $0,35 \mathrm{GHz}$ & $1 \mathrm{GHz}$ & $1.6 \mathrm{GHz}$ & $2.4 \mathrm{GHz}$ & $4.8 \mathrm{GHz}$ \\
\cline { 2 - 6 } & & & & & \\
\hline \multirow{2}{*}{ RAM } & $256 \mathrm{MB}$ & $512 \mathrm{MB}$ & $1 \mathrm{~GB}$ & $2 \mathrm{~GB}$ & $4 \mathrm{~GB}$ \\
\hline \multirow{2}{*}{$\mathrm{HDD}$} & $20 \mathrm{~GB}$ & $40 \mathrm{~GB}$ & $80 \mathrm{~GB}$ & $120 \mathrm{~GB}$ & $240 \mathrm{~GB}$ \\
\cline { 2 - 6 } & & & & & \\
\hline \multirow{2}{*}{ VRam } & $16 \mathrm{MB}$ & $64 \mathrm{MB}$ & $256 \mathrm{MB}$ & $512 \mathrm{MB}$ & $1 \mathrm{~GB}$ \\
\cline { 2 - 6 } & & & & & \\
\hline \multirow{2}{*}{ Ethernet } & $56 \mathrm{Kbs}$ & $10 \mathrm{Mbs}$ & $100 \mathrm{Mbs}$ & $1 \mathrm{Gbs}$ & $10 \mathrm{Gbs}$ \\
\cline { 2 - 6 } & & & & & \\
\hline
\end{tabular}




\begin{tabular}{|l|c|c|c|c|c|}
\hline \multirow{2}{*}{ How often you use PC for spreadsheets } & Low & & & & High \\
\cline { 2 - 7 } & never & yearly & monthly & weekly & daily \\
\hline & 0 & 1 & 2 & 3 & 4 \\
\hline
\end{tabular}

\section{Part 2. The surveys' forms}

\section{Form 2: Consider the following PC:}

\section{AMD 64 Professional Pack: AMD Athlon 64 4800+ Quad Core}

\section{Hardware}

- $\quad$ 107S 17" Flat Screen Beige or Black

- PowerColour X300SE 64MB PCI Express Video Card

- 2 GB DDR 400 RAM

- Seagate 160GB Serial ATA Hard Drive

- Samsung Internal IDE 52/24/52 CDRW

- 3.5" Floppy Drive

- 56 kbps V92 PCI Fax Modem

- Integrated 10/100 Network Card

- Microsoft Multimedia Keyboard

- Microsoft Optical Wheel Mouse

- Microsoft Windows XP Home Edition OEM

\section{Bundled Software}

- $\quad$ Microsoft Windows XP Home

- $\quad$ Open Office ver 2 consisting of:

- $\quad$ Calc - MS Excel-compatible spreadsheet

- $\quad$ Writer - MS Word-compatible word processor

- Impress - MS Powerpoint-compatible presentations

- Draw - Drawing program

- $\quad$ AVG Antivirus

We need your input on the following:

1. Please fill in the table below by ticking the box that best represents your needs in order to perform the stated task (listed in the first column) and your opinion on the extent to which the offered computer is capable of satisfying them.

\begin{tabular}{|c|c|c|c|c|c|c|c|c|c|c|}
\hline & \multicolumn{5}{|c|}{ Degree of your needs } & \multicolumn{5}{|c|}{ The PC degree of capability } \\
\hline & \multicolumn{5}{|c|}{ Low $\ldots . . \ldots \ldots \ldots \ldots . .$. High } & \multicolumn{5}{|c|}{ Low ..........................High } \\
\hline & $\overline{0}$ & 1 & $\overline{2}$ & 3 & 4 & 0 & $\overline{1}$ & 2 & 3 & $\overline{4}$ \\
\hline Using word proces & & & & & & & & & & \\
\hline Using spreadsheets & & & & & & & & & & \\
\hline Using e-mail & & & & & & & & & & \\
\hline Surfing Internet & & & & & & & & & & \\
\hline Solving complicate & & & & & & & & & & \\
\hline Playing Games & & & & & & & & & & \\
\hline Watching movies & & & & & & & & & & \\
\hline Listening to Music & & & & & & & & & & \\
\hline
\end{tabular}




\section{Specific part: Survey 1}

Which warranty option would you prefer for your purchase? Please, choose ONE of the options listed below, by ticking the box on the right:

\begin{tabular}{|l|l|}
\hline $\begin{array}{l}\text { The PC is replaced or repaired free of charge to the customer if it fails within the } \\
\text { first THREE years after the sale date. }\end{array}$ & \\
\hline $\begin{array}{l}\text { The customer will get full refund if he/she is not fully satisfied with the PC within } \\
\text { the first THREE months after the sale date. }\end{array}$ & \\
\hline
\end{tabular}

\section{Specific part: Survey 2}

Which warranty option would you prefer for your purchase? Please, choose ONE of the options listed below, by ticking the box on the right:

\begin{tabular}{l}
\hline \begin{tabular}{l|} 
The PC is replaced or repaired free of charge to the customer if it fails within the \\
first THREE years after the sale date.
\end{tabular} \\
$\begin{array}{l}\text { The customer will get full refund if he/she is not fully satisfied with the PC within } \\
\text { the first THREE months after the sale date. }\end{array}$ \\
\hline $\begin{array}{l}\text { The customer will get full refund if he/she is not fully satisfied with the PC within } \\
\text { the FIRST month after purchasing AND } \\
\text { the PC is replaced or repaired free of charge to the customer if it fails within ONE } \\
\text { year after the sale date. }\end{array}$
\end{tabular}

\section{Biographies}

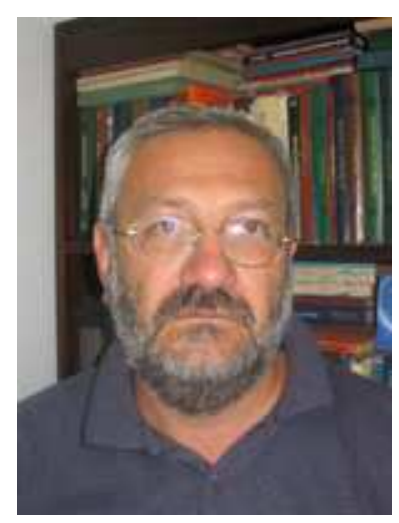

Dimitar Christozov is a Professor of Computer Science at the American University in Bulgaria, Blagoevgrad 2700, Bulgaria since 1993, email: dgc@aubg.bg. He has more than 25 years of experience in areas as computer science, quality management and information systems. He graduated Mathematics from Sofia University "St. Kliment Ohridski" in 1979. He completed his PhD thesis "Computer Aided Evaluation of Machine Reliability" in 1986. In ICTT "Informa" (1986-1993) Dr. Christozov was involved in establishing the national information network for technology transfer and research in the areas of technologies assessment, integral quality measures and information systems for quality management. In these areas he was recognized as one of the leading experts in Bulgaria. Professor Christozov has more than 50 publications as separate volume, journal papers and papers in refereed proceedings. He is a founding member of Informing Science Institute and chair of Bulgarian Informing Science Society; and member of the Bulgarian Statistical Society.

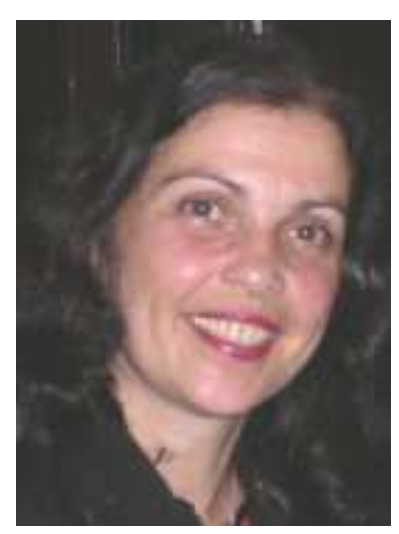

Dr. Stefanka Chukova is a Reader in Statistics and Operations Research at the School of Mathematics, Statistics and Computer Science, Victoria University of Wellington, Private Bag 600, Wellington, New Zealand, e-mail: schukova@mcs.vuw.ac.nz. She has a PhD and MSc in Mathematics (concentration in Probability and Statistics) and BSc in Mathematics from University of Sofia, Sofia, Bulgaria. Her research interests are in applied stochastic models, warranty analysis, reliability and queueing. She has more than 50 publications and has presented papers at national and international conferences. She is a member of ORSNZ, AWIS and ASA. 


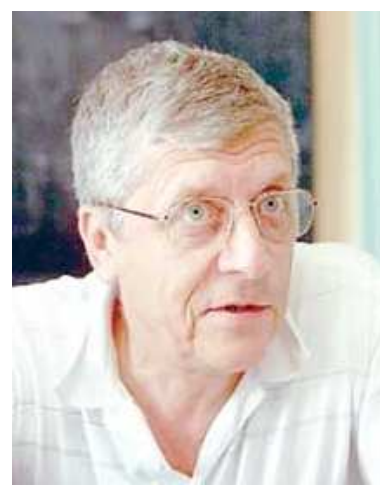

Dr.Plamen S. Mateev is Associate professor in Faculty of Mathematics and Informatics, Sofia University "St.Kliment Ohridski", Department "Probability, Operation Research, Statistics", Bulgaria, 1164 Sofia, 5, J.Boucher str., e-mail: pmat@fmi.uni-sofia.bg.

His MSc in Mathematical Statistics is from Sofia University and his $\mathrm{PhD}$ is from Moscow State University. The research interests are in communication theory, applied statistics, statistical software and applications. More than 70 papers are published in scientific journals and proceedings of scientific conferences. He is the Chair of Bulgarian Statistical Society and member of ENBIS and Bulgarian Informing Science Society. 